\title{
Trust Toward Robots and Artificial Intelligence: An Experimental Approach to Human-Technology Interactions Online
}

\section{OPEN ACCESS}

Edited by:

Mohamed Chetouani, Université Pierre et Marie Curie,

France

Reviewed by:

Patrícia Alves-Oliveira,

University of Washington,

United States

Mojgan Hashemian,

University of Tehran, Iran

Stephanie M. Merritt,

University of Missouri-St. Louis,

United States

*Correspondence: Atte Oksanen

atte.oksanen@tuni.fi

Specialty section:

This article was submitted to

Human-Media Interaction,

a section of the journal

Frontiers in Psychology

Received: 19 June 2020 Accepted: 04 November 2020

Published: 03 December 2020

Citation:

Oksanen A, Savela N, Latikka R and Koivula A (2020) Trust Toward Robots and Artificial Intelligence: An Experimental Approach to Human-Technology Interactions Online. Front. Psychol. 11:568256. doi: 10.3389/fpsyg.2020.568256

\author{
Atte Oksanen ${ }^{1 *}$, Nina Savela ${ }^{1}$, Rita Latikka ${ }^{1}$ and Aki Koivula ${ }^{2}$ \\ ${ }^{1}$ Faculty of Social Sciences, Tampere University, Tampere, Finland, ${ }^{2}$ Faculty of Social Sciences, University of Turku, Turku, \\ Finland
}

Robotization and artificial intelligence (Al) are expected to change societies profoundly. Trust is an important factor of human-technology interactions, as robots and Al increasingly contribute to tasks previously handled by humans. Currently, there is a need for studies investigating trust toward Al and robots, especially in first-encounter meetings. This article reports findings from a study investigating trust toward robots and $\mathrm{Al}$ in an online trust game experiment. The trust game manipulated the hypothetical opponents that were described as either Al or robots. These were compared with control group opponents using only a human name or a nickname. Participants ( $N=1077$ ) lived in the United States. Describing opponents with robots or Al did not impact participants' trust toward them. The robot called jdrx894 was the most trusted opponent. Opponents named "jdrx894" were trusted more than opponents called "Michael." Further analysis showed that having a degree in technology or engineering, exposure to robots online and robot use self-efficacy predicted higher trust toward robots and Al. Out of Big Five personality characteristics, openness to experience predicted higher trust, and conscientiousness predicted lower trust. Results suggest trust on robots and $\mathrm{Al}$ is contextual and it is also dependent on individual differences and knowledge on technology.

Keywords: trust, human-technology interaction, robot, artificial intelligence, individual differences, trust game

\section{INTRODUCTION}

Robotization and artificial intelligence (AI) are expected to change societies profoundly (Borenstein, 2011; Liu and Zawieska, 2017; Makridakis, 2017). Robots and AI are expected to become more humanlike and to handle tasks normally performed by individuals (Goetz et al., 2003; Frey and Osborne, 2017). Huang et al. (2019) argued that there is an on-going shift from the current thinking economy to a feeling economy. In the longer run, AI is likely to contribute to communicating, interacting, and empathizing tasks formerly performed by humans (Huang and Rust, 2018; Huang et al., 2019). Intelligent chatbots are already a working example of this process.

We argue that analyzing trust in human-technology relationships is important to understand the transformative change brought on by AI and new-generation social robots. Trust is essential in human interactions and human well-being, and without trust, human societies would not function in a civilized manner (Putnam, 2000; Cook, 2001; Uslaner, 2002; Hardin, 2005). Trust is equally 
important in technological encounters (Hancock et al., 2011; Sanders et al., 2011; Schaefer et al., 2016). Existing literature shows that humans are more willing to accept new technologies, such as robots, when they have prior experience (Venkatesh, 2000; Nomura et al., 2006; Bartneck et al., 2007; Heerink et al., 2010) and self-efficacy in handling them (Hsu and Chiu, 2004; Hasan, 2006; Rahman et al., 2016; Latikka et al., 2019). There is a current need for studies investigating trust toward AI and robots, especially in first-encounter situations involving little information about the other actor.

This article reports the results based on a trust game experiment involving robots and AI. Our aim was first to analyze whether participants show lower trust toward robots and AI than toward others given only name or nickname but not described as a robot or AI. Furthermore, our study aimed to explore how trust functions in human-technology interaction, while considering different social psychological factors, such as robot use selfefficacy and personality.

\section{Trust in Human-Technology Interactions}

Trust has psychological and sociological dimensions. From developmental psychology, researchers know that humans build basic trust toward those closest to them, and later, they are taught to understand how much and in whom they should trust (Simpson, 2007b; Van Lange, 2015). In sociology, trust is considered to be the social glue that brings people and good things in societies together (Putnam, 2000; Uslaner, 2000; Rothstein and Uslaner, 2005; Bjørnskov, 2012).

Trust can be divided into trust in people close to individuals (family, friends, and colleagues) and trust in people who are more distant from individuals (people in general or strangers). Distinctions, such as intimate versus abstract trust (Freitag and Traunmüller, 2009), thick versus thin trust (Putnam, 2000), and particularized versus generalized trust (Stolle, 2002; Uslaner, 2002), characterize these different dimensions of trust. Intimate trust is universal, whereas generalized trust depends on the circumstances. In their seminal work on trust in automation, Lee and See (2004) defined trust "as the attitude that an agent will help achieve an individual's goals in a situation characterized by uncertainty and vulnerability" (p. 51).

Advanced technology, such as AI, causes complex challenges, due to their intelligence and potentially hidden motivations. Simple machines of previous decades could be trusted on the basis that they worked as expected, but intelligent machines, such as new robots or other AI solutions, cause potential concerns. On what premise should people trust them? Who programmed them? What have they learned from humans already? Are their purposes good or bad? These questions are one reason that the ethics of AI are currently being discussed intensively (Russell et al., 2015; Dignum, 2018; Winfield et al., 2019). There is, however, nothing new in these discussions, as similar concerns have been raised before. For example, computers were suspected to have negative effects on humanity and society (Simon, 1977), and indeed, they have been found to cause anxiety for some (Fariña et al., 1991).

A literature review by Sanders et al. (2011) showed that robot type, functionality, level of automation, and personality impact how they are trusted: People show higher trust when a robot looks as expected and when certain anthropomorphic features, such as gestures and emotional expressions that are likely to increase trust, are included. Also, robot personality is associated with trust, and people tend to trust robots that have likeable features. People tended to more often trust robots that showed more positive emotion (Mathur and Reichling, 2016). In a recent experiment, a robot apologizing for its mistake was considered more likeable, but less capable. Likability and warmth-based trust had a positive effect on intentions to use the robot again (Cameron et al., 2021).

Robots are typically defined by their physical characteristics (see, for example, International Organization for Standardization [ISO], 2014), but AI can function via any technological apparatus and it is more hidden and integrated. In contrast to physical robots, the concept of bot refers to online agents and software applications that can also use AI and simulate human interaction, for example intelligent chatbots (e.g., Mitsuku and Alisa). Previous studies have shown that an extensive amount of visual images of robot affects how they are perceived (Fortunati et al., 2015). This may cause trust toward AI to be more abstract than trust toward robots. Another possible influencing factor consists of the differences between how fictive robots are represented and how real robots are designed. People have become familiar with fictive robots, such as R2-D2 and C3PO in Star Wars, and real ones, such as Paro and Nao, who embody harmless and petlike appearances. In contrast to these, AI is often portrayed as a higher-level operator in popular fiction, such as in 2001: A Space Odyssey by Stanley Kubrick and Her by Spike Jonze.

Studies on computer interfaces show that people often treat computer interfaces as though they are human, especially in the research on the computers are social actors paradigm (Reeves and Nass, 1996; Nass and Moon, 2000). Based on research conducted since the 1990s, introducing familiar characteristics to technology seems to be decisive in computer interface success, as people are more willing to be drawn toward others who are similar to them (Reeves and Nass, 1996; Nass and Moon, 2000; Nass and Lee, 2001). This similarity-attraction hypothesis has been widely tested in social psychology (Montoya and Horton, 2013).

Trust always has a social and operational context or environment. How much people trust technology, such as robots and AI, depends on where they are used. Trust as a behavior (B) is a function of a person (P) and their environment (E), including the object to be trusted, according to Levin, 1935, p. 73) classic equation of factors explaining behavior: $B=f(P$, $E$ ). For example, people may consider service robots in hospitals trustworthy if they trust hospitals in general. Situational and environmental aspects may also influence the trust people have. In some situations, however, it is challenging for people to judge the intentions of other people who have designed robots or AI. These types of situations may occur for people who browse online and meet chatbots or other agents using AI.

Aside from previously stated robot-related aspects, humanrelated factors impact the extent to which people trust robots and AI (Hancock et al., 2011; Schaefer et al., 2016). Older people trust robots and other automated processes less than younger people (Hoff and Bashir, 2015), which is consistent with the findings showing that older people harbor more negative 
emotions toward robots and are more reluctant to support the use of AI or service robots (Scopelliti et al., 2005; Eurobarometer, 2012; Zhang and Dafoe, 2019). Previous studies have not found consistent differences between genders regarding trust toward robots (Hoff and Bashir, 2015). However, women tend to show more negative attitudes toward robots and are less willing to work with robots (De Graaf and Allouch, 2013; Reich and Eyssel, 2013; Reich-Stiebert and Eyssel, 2015).

Employment status, household income, and educational background are factors that determine people's access and usage of new technologies (Van Deursen and Van Dijk, 2014), and they are crucially linked to how much people trust other people (Delhey and Newton, 2003). Recent research on humantechnology interactions has shown that people's attitudes toward robots and AI vary according to employment status and household income (Gnambs and Appel, 2019; Zhang and Dafoe, 2019). Education and interest in technology are also essential factors behind acceptance of and confidence in new technologies (Heerink, 2011).

Robot use self-efficacy has a potential impact on trust. Selfefficacy refers to an individual's beliefs about their ability to perform in a particular situation or task (Bandura, 1986, 1997) and has been studied throughout the history of technological advances (Compeau and Higgins, 1995; Agarwal et al., 2000; Hasan, 2006; Rahman et al., 2016), including the Internet (Eastin and LaRose, 2000; Hsu and Chiu, 2004). In the context of robotbased technology, robot use self-efficacy has been found to be a separate construct from general self-efficacy and has been found to predict the acceptance of robots in a health care context (Latikka et al., 2019; Turja et al., 2019).

Last, personality traits impact trust and the ways in which people use technology. Personality impacts, for example, what kinds of robots people find likeable and trustworthy (Sanders et al., 2011; Correia et al., 2019). Currently, the five-factor model of personality (the Big Five) is most widely used and accepted (Digman, 1990; John et al., 2008). Studies on trust and personality show that high agreeableness has a positive relationship with high interpersonal trust (Mayer et al., 1995; Mooradian et al., 2006). Some evidence also suggests a positive correlation between trust and openness (Kaplan et al., 2015). Personality has been noted in studies on trust and technology, but findings remain limited (Hancock et al., 2011; Schaefer et al., 2016). Evidence suggests that extroverts are more receptive of robots and that low neuroticism is connected to the acceptance of robots (Robert, 2018). Another study found a relationship between increased trust in automation and high agreeableness or conscientiousness (Chien et al., 2016).

\section{Measuring Trust With a Trust Game}

The trust game is an experimental method of measuring trust as investment decisions. It originates from the investment game, originally introduced by Berg et al. (1995), in which trust and reciprocity are assessed in an economic exchange relation. Previous studies have indicated that people's motivation to reciprocate trust is determined not only by maximization of personal goals but also by consideration of consequences for both self and others (Fehr and Gintis, 2007; Van Den Bos et al., 2009). In the trust game, the consequences of trust are determined concretely by the amount of money that participants are willing to give up (Berg et al., 1995; Evans and Revelle, 2008).

The literature on trust research includes many variations of the trust game (Trifletti and Capozza, 2011; Samson and Kostyszyn, 2015; Xin et al., 2016). In general, the player receives a certain amount of money and chooses how much of that money to send to the opponent. The money received by the opponent is multiplied and the opponent can decide to keep the money or return part or all of it. The amount of money transferred, if any, measures the investment decision, that is the trust behavior. In a simpler format, the player receives a certain amount of money and decides how much of that money to give to the described opponent (Berg et al., 1995; Evans and Revelle, 2008).

Results of the trust game have been shown to correlate with trust and are thus not limited solely to economic decisions (Dunning et al., 2012) or altruistic behavior (Brülhart and Usunier, 2011). However, measuring trust is broadly discussed and challenged because trust has such a wide variety of definitions (Hardin, 2005). The trust phenomenon is complex and consists of three to four parts as $A$ trusts that $B$ is/makes $X$, to which condition $\mathrm{Z}$ can be added. Changing any of these dimensions may have an effect on the resulting trust (Simpson, 2007a). Furthermore, there is also a paradox of information in trust: When trust presupposes a lack of information, it is also based on information (e.g., on experience and conditions), which may lead to difficulties in examining the degree of trust (Nooteboom, 2011).

However, trust can evolve from expected reciprocity (Ashraf et al., 2006). Reciprocity, in turn, is expected more when the cues for personal identity are present. At a group level, reciprocity is expected more from ingroup members than outgroup members when social identity is salient (Tanis and Postmes, 2005). The use of a person's first name as a relatively minimal social cue enables the generation of positive interpersonal impressions (Tanis and Postmes, 2003).

The trust game is adaptable to different studies on societal and psychological phenomena, such as usage and trust of new technologies. The trust game was originally developed in the context of investment decisions (Berg et al., 1995), which limits the perfection of its fit to other areas. Further, as a two-player one-time game it may not capture all complex dynamics around the decisions to trust (Camerer, 2003, p. 85; Dunning et al., 2012). However, trust measured via survey items associates positively with investing money in the trust game (Evans and Revelle, 2008). The trust game is popular among trust scholars (Johnson and Mislin, 2011), and useful for experimental research designs that aim to understand contextual variations of trusting others. The benefit of the trust game, as an experiment, is its measurement of actual behavior, which may give a relatively reliable indication of how people function in a real-life context. Despite previous studies on trust in technologies (Hancock et al., 2011, 2020; Schaefer et al., 2016), many of these studies have focused on using traditional survey measures (e.g., Yagoda and Gillan, 2012) and only a few studies used experiments to investigate trust in technologies (e.g., Correia et al., 2016, 2019; Ferreira et al., 2016). The trust game has not been utilized to analyze trust in robots and AI before. 


\section{This Study}

This study tested whether participants show trust in robots and $\mathrm{AI}$ and it used an experimental trust game design. Our research question was: Do participants trust robots or AI less than control group members not specified as a robot or AI? The trust game manipulated the hypothetical opponents that were described as either robots or AI. These were compared with control group opponents using only human name or nickname. The main hypotheses of the study were preregistered at the Open Science Framework before collecting the data (Oksanen et al., 2019).

The hypotheses were based on a similarity-attraction hypothesis underlining that people are more likely to be drawn toward those similar to them (Montoya and Horton, 2013). Further, based on the existing literature, we expected that participant would show lower trust on robots and AI, because they are still emerging technologies and people are not necessarily familiar with their operational logic and intentions. In other words, our hypotheses were based on trust research indicating that people show more trust toward things that they are familiar with (Gefen, 2000; Hancock et al., 2011). Originally the hypothesis pre-registration specified control group opponents as humans, but we updated this to unspecified control group to reflect the fact that growing relevance of different AI agents could also lead people to interpret the control group opponent as non-human. Our hypotheses are then as follow:

H1: Respondents trust robot opponents less than control opponents who are not specified as either human or non-human.

$\mathrm{H} 2$ : Respondents trust AI opponents less than control opponents who are not specified as either human or non-human.

H3: Respondents trust opponents with a human name more than opponents with a nickname.

The second part of the analysis focused on investigating the correlations of the trust expressed in the trust game. The aim was to analyze individual differences in trust of robots and AI. We expected that technology education (H4), robot exposure online (H5), and robot use self-efficacy (H6) would predict higher trust toward robots and AI. These were generally based on studies on trust showing that trust is grounded in personal social interaction experiences (Van Lange, 2015) and empirical evidence on trust toward technology, automation, and robots (Hancock et al., 2011; Schaefer et al., 2016). Additionally, we expected (H7) that personality traits, such as agreeableness, conscientiousness, openness, and extraversion, would have a positive relationship and that neuroticism would have a negative relationship with trust toward robots and AI (Mayer et al., 1995; Mooradian et al., 2006; Kaplan et al., 2015; Chien et al., 2016; Robert, 2018).

\section{MATERIALS AND METHODS}

\section{Participants}

Data were collected in April 2019 from American participants $\left(N=1077,50.60 \%\right.$ female, $M_{\text {age }}=37.39$ years, $S D_{\text {age }}=11.42$ years) who were recruited via Amazon's Mechanical Turk, which is considered a reliable source to obtain research participants in the United States (Buhrmester et al., 2011; Paolacci and Chandler, 2014; Huff and Tingley, 2015). Recent analysis also showed that the financial situation of MTurk participants mirrors that of the United States and that respondents do not find requesters abusive (Moss et al., 2020). Some concerns have arisen, however, due to non-United States residents trying to access the surveys intended for United States residents only. We used the procedure suggested by Kennedy et al. (2020) and excluded non-United States participants from the data. We also checked the data for respondents with odd response behavior (e.g., who finished the survey too quickly or selected the same answer option throughout the survey).

The participants were from 50 states, with the highest response rates coming from California (8.08\%), New York (7.89\%), Florida (7.80\%), and Texas (7.06\%). The population was $72.52 \%$ White (not Hispanic), 6.22\% African American (not Hispanic), 13.09\% Hispanic, and $5.94 \%$ Asian. These figures are close to the United States population estimates, except that the African American population was under-represented (U. S. Census Bureau, 2010). In addition, participants have, on average, higher educational attainment than the population in general, as $66.07 \%$ of participants 25 years and older had a college degree, but only $39.20 \%$ in the population have achieved this education level. Higher educational attainment of Mechanical Turk respondents has been previously noted (Huff and Tingley, 2015; Hitlin, 2016).

\section{Procedure}

In this between-subjects design study, survey respondents were asked to provide sociodemographic and personality information before entering the experiment. After the experiment, they were asked about their experience in using robots and their robot attitudes. Median response time for the whole survey, including the experiment, was $8 \mathrm{~min}$ and $10 \mathrm{~s}(M=9 \mathrm{~min}$ and $58 \mathrm{~s})$ and $44 \mathrm{~s}$ for the experiment only $(M=1 \mathrm{~min}$ and $9 \mathrm{~s})$. Survey respondents received a small reward of $\$ 0.90$ for their participation. The academic ethics committee of Tampere Region in Finland stated, in December 2018 (statement 89/2018), that the research project did not involve ethical problems.

At the beginning of the trust game, the participants (i.e., players) were told of a hypothetical situation in which they were given $\$ 1,000$ and could decide to keep the whole sum or share part of it with their opponent. They were told that the experimenter would triple the amount of money they gave (i.e., if they gave $\$ 500$, the other player would receive $\$ 1,500$ ). Then, they were told that their opponent could freely decide whether to return any money to the participant player. At the end of the explanation, we asked the participants to fill in a box containing an amount between $\$ 0$ and $\$ 1,000$ (see Appendix A). The opponent did not have to take action in this hypothetical situation; only the participant was asked to choose an action.

Respondents were randomly assigned to one of six groups at the beginning of the experiment. The trust game included manipulation of hypothetical opponents; they were described as either AI or robots and compared with control group opponents, which used only human names or nicknames. Opponents were introduced as robots (Michael or jdrx894), AI (Michael or jdrx894), or only by name (Michael or jdrx894). We carried out the manipulations by adding the words "robot" or 
"artificial intelligence”-for example, “opponent name: jdrx894, a robot" or "opponent name: jdrx894, an artificial intelligence." The experimental conditions were compared with two control group opponents who were introduced with only a human name (Michael) or a nickname (jdrx894) without calling them robots or AI.

An analysis of the basic characteristics of the robot (Michael: $n=192$; jdrx894: $n=172$ ) and AI (Michael: $n=185$; jdrx894: $n=171$ ) experimental groups and control groups (Michael: $n=171$; jdrx894: $n=186$ ) showed that the randomization was successful and that no statistically significant differences in gender, age, education or Big Five personality traits were present.

\section{Measures \\ Trust}

The amount of money given to the opponent in the trust game was the outcome variable, considered to measure a participant's trust toward their opponent. This variable ranged from $\$ 0$ to $\$ 1,000$. The mode value for all groups was $\$ 500$. There were no issues with skewness in any of the six groups (from 0.04 to 0.37 ), but kurtosis figures indicated light-tailed distribution (from 1.97 to 2.39 when 3 equals the normal distribution). A Shapiro-Wilk test showed that only one group out of six was normally distributed.

\section{Sociodemographic Variables}

We used sociodemographic variables as independent variables in the second part of the study. They included age, gender, employment status, household gross annual income, and degrees in technology or engineering.

\section{Robot-Related Variables}

The second part of the study included also several variables on robots. Exposure to robots online was measured with the question, "Have you heard, read, or seen anything about robots in social media, internet forums, or blogs?" (No/Yes). The robot use self-efficacy scale was based on the RUSH-3 scale (Turja et al., 2019) and included three statements on a scale from 1 (strongly disagree) to 7 (strongly agree). The statements used in this study were (a) "I'm confident in my ability to learn how to use robots," (b) "I'm confident in my ability to learn the simple programming of robots if I were provided the necessary training," and (c) "I'm confident in my ability to learn how to use robots in order to guide others to do the same." The measure showed good reliability based on Cronbach's alpha $(\alpha=0.88)$, and the final sum variable ranged from 3 to 21 . Previous experience with robot use was determined with a single-item question: "Have you ever used a robot or interacted with a robot?"

\section{Personality}

For the second part of the study, we measured personality traits with a 15-item Big Five inventory, in which participants scored statements on a scale from 1 to 7 (Lang et al., 2011). For each personality trait, we created a 3-item sum variable ranging from 3 to 21 . Interitem reliability figures ranged from good to acceptable: neuroticism $(\alpha=0.85)$, extroversion
( $\alpha=0.84)$, openness $(\alpha=0.79)$, agreeableness $(\alpha=0.62)$, and conscientiousness ( $\alpha=0.67)$.

\section{Statistical Techniques}

We conducted all analyses with Stata 16. Because violation of normality was moderate and our sample was large $(N=1077)$, we decided to run analyses using a parametric one-way and twoway ANOVA. Negative kurtosis is not considered a problem with larger samples (Waternaux, 1976; see also Tabachnick and Fidell, 2013; Gravetter and Wallnau, 2017). In addition, our experiment and control groups were relatively equal in size. Also, the results of Bartlett's test for equal variance were insignificant, indicating that experiment and control groups had similar variation $\left(\chi^{2}[5]=2.75, p=0.739\right)$. We conducted a robustness check by running a non-parametric Kruskal-Wallis $H$ test. As these results showed no deviation from the parametric tests, we only report the parametric one-way and two-way ANOVA tests.

The second part of the study was based on ordinary least squares regression. Unstandardized regression coefficients $(B)$ and their standard errors $(B S E)$, standardized beta coefficients $(\beta), p$-values, model goodness-of-fit measures $\left(R^{2}\right)$, model test $(F)$, and $p$-values were reported. We did not detect problematic multicollinearity. A Breusch-Pagan test for heteroskedasticity showed no problems with heteroskedasticity of residuals $\left(\chi^{2}=0.65, p=0.42\right)$. Residuals were also considered as having normal distribution (skewness $=0.22$, kurtosis $=0.237$ when 3 = normal distribution). We detected outliers by looking at Cook's distance measure, where values greater than $4 / \mathrm{N}$ may cause problems. Due to the existing outliers, we also ran the model with a robust regression considered to be a solution for cases in which outliers are present (Verardi and Croux, 2009). The results by robust regression run with a rreg command in Stata are reported in the Appendix B, as they did not change any of the results.

\section{RESULTS}

The descriptive statistics in Table $\mathbf{1}$ and Figure $\mathbf{1}$ show that the opponent described as "jdrx894, a robot" was given the highest sum of money on average, and the lowest sum of money was given to the opponent called Michael. The one-way ANOVA results for the six groups showed statistically significant differences between groups $[F(5,1071)=3.17, p=0.008]$. A pairwise comparison of means using Tukey's honest significant

TABLE 1 | Descriptive statistics on the amount of money given in the experimental and control groups in Study $1(N=1077)$.

\begin{tabular}{lcccccc}
\hline Group & $\boldsymbol{n}$ & $\%$ & $\boldsymbol{M}$ & SD & Md & Range \\
\hline Al: Michael & 185 & 17.18 & 454.50 & 300.44 & 500 & $0-1000$ \\
Al: jdrx894 & 171 & 15.88 & 492.78 & 328.83 & 500 & $0-1000$ \\
Robot: Michael & 192 & 17.83 & 459.80 & 321.58 & 478 & $0-1000$ \\
Robot: jdrx894 & 172 & 15.97 & 540.33 & 316.55 & 500 & $0-1000$ \\
Control: Michael & 171 & 15.88 & 415.95 & 299.23 & 450 & $0-1000$ \\
Control: jdrx894 & 186 & 17.27 & 489.08 & 303.74 & 500 & $0-1000$
\end{tabular}




\section{Interval Plot of the Money Given by the Experimental Groups}

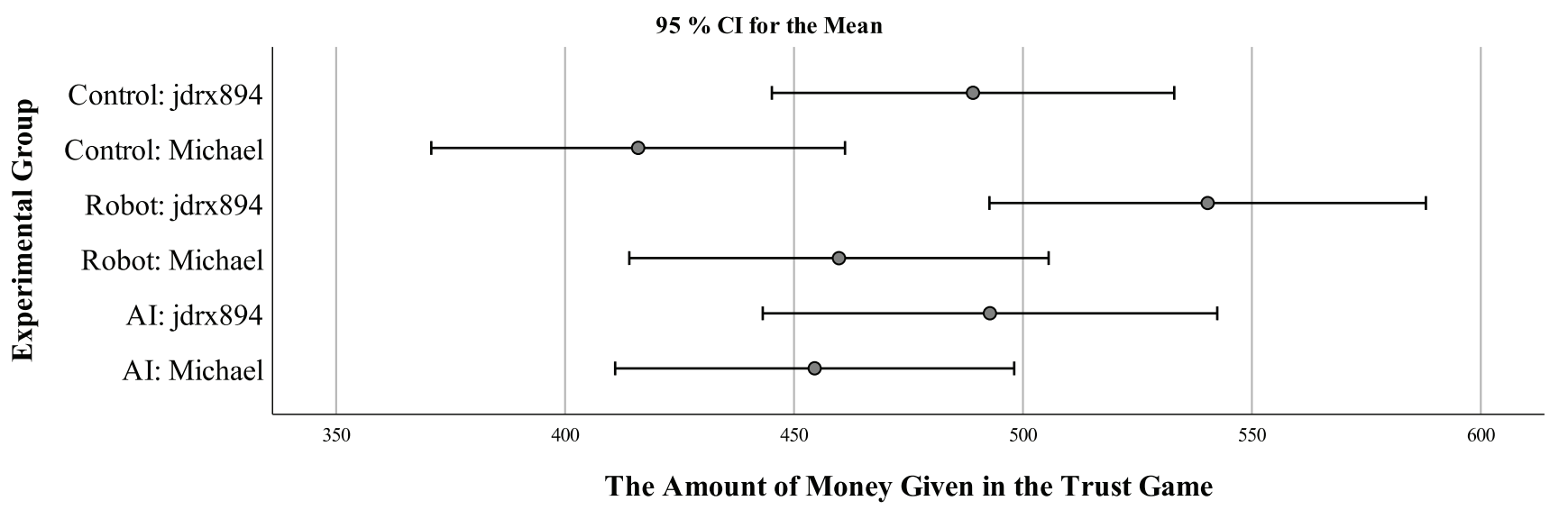

FIGURE 1 | Trust game mean values $(95 \% \mathrm{Cl})$ on a scale of $0-1000$ by experimental groups in Study $1(N=1077)$.

difference test indicated that jdrx894 robot $(M=540.33)$, received more money than Michael $(M=415.95, p=0.003)$ in the control group.

Two-way ANOVA was run to analyze the effect of name (Michael or jdrx894) and type of the opponent (robot, AI or control) (see Table 2). There were no statistically significant differences between three types of opponents. Opponents called Michael were trusted less, $F(1,1071)=11.31, p=0.001$. Analysis of adjusted means based on the ANOVA model showed that jdrx894 received $\$ 507.40$, but Michael only received $\$ 444.42$.

The second part of the analysis was focused on analyzing the correlations of the trust expressed in robots and AI $(n=720)$. Participants in robot and AI conditions were combined due to the fact that previous analysis showed no statistically significant differences between them. Results were also similar in regression models and there were no statistically significant interactions between conditions. The average sum of money given to the robot or AI opponents was $\$ 485(M=485.51$, $S D=318.00$, range $\$ 0-\$ 1,000)$. Table 3 contains details on independent variables, excluding control groups that were not used in the second part of the analysis. There were some notable differences between participants. For example, those with degrees in engineering or technology gave an average of

TABLE 2 | Two-way analysis of variance of money given in the trust game in the experimental groups and control groups in Study $1(N=1077)$.

\begin{tabular}{lccccc}
\hline Measure & df & MS & $\boldsymbol{F}$ & $\boldsymbol{p}$ & $\boldsymbol{\eta}_{\mathbf{p}}^{\mathbf{2}}$ \\
\hline Type & 2 & 204267.63 & 2.10 & 0.123 & - \\
Name & 1 & 1099834.3 & 11.31 & 0.001 & 0.01 \\
Type $\times$ name & 2 & 45485.881 & 0.47 & 0.627 & - \\
Residual & 1,071 & 97262.353 & & & \\
Total & 1,076 & 98244.876 & & &
\end{tabular}

Name (Michael or jdrx894) and type (robot, Al or unspecified control) refer to the opponents; MS, mean squares.
$\$ 530$, and others gave an average of $\$ 471$. The regression model shown in Table 4 further analyzes which sociodemographic and social-psychological factors were associated with giving money to an opponent. The model was statistically significant, and the included variables explained $9 \%$ of the variance $\left(R^{2}=0.09\right.$, $F=4.90, p<0.001)$.

Age (40 years or more; $\beta=0.13, p<0.001)$ and technology/engineering degree $(\beta=0.08, p=0.045)$ were also associated with giving money to robots and AI when adjusting for a number of other factors. We also noted that participants in both low- and high-income brackets gave less money to robot and AI opponents. However, we found statistical significance only when comparing the $\$ 35,000-\$ 154,999$ income group to households with a gross annual income of less than $\$ 35,000$ $(\beta=-0.08, p=0.034)$.

The findings also indicated that participants who were exposed to robots online gave more money to robots and AI opponents $(\beta=0.07, p=0.046)$. The single most important predictor for giving money to an AI or robot was robot use self-efficacy $(\beta=0.16, p<0.001)$. Personality traits of neuroticism, extroversion, and agreeableness were not statistically significant. However, those showing openness to experiences gave more money to robot or AI opponents $(\beta=0.09$, $p=0.022$ ), and those showing conscientiousness gave less money $(\beta=-0.14, p=0.003)$.

We used the last model to seek the potential exposure effects of previous experience with robots. One-third of participants (33.19\%) reported such experience. The interaction term between robot use experience and robot use self-efficacy was added to the model. The model was statistically significant, and $10 \%$ of the variance was explained $\left(R^{2}=0.10, F=4.60, p<0.001\right)$. Results showed that the variables that were statistically significant in the previous model remained so (see Appendix C). Thus, noting previous robot use experience did not change the results in any way. However, the interaction term was negative $(\beta=-0.40, p=0.038)$, indicating that those who had robot use experience and high robot use self-efficacy gave lower sums of 
TABLE 3 | Descriptive statistics of independent variables used for regression analyses $(N=720)$.

\begin{tabular}{|c|c|c|c|c|c|}
\hline Categorical measures & $n$ & $\%$ & & & \\
\hline \multicolumn{6}{|l|}{ Age } \\
\hline$<40$ & 484 & 67.22 & & & \\
\hline 40 and over & 236 & 32.78 & & & \\
\hline \multicolumn{6}{|l|}{ Gender } \\
\hline Female & 353 & 49.03 & & & \\
\hline Male & 357 & 49.58 & & & \\
\hline Other/not specified & 10 & 1.39 & & & \\
\hline \multicolumn{6}{|l|}{ Occupational status } \\
\hline Student & 20 & 2.78 & & & \\
\hline Works full or part time & 611 & 84.86 & & & \\
\hline Other & 89 & 12.36 & & & \\
\hline \multicolumn{6}{|l|}{$\begin{array}{l}\text { Household's gross annual } \\
\text { income }\end{array}$} \\
\hline$<\$ 35,000$ & 190 & 26.39 & & & \\
\hline$\$ 35,000-\$ 154,999$ & 495 & 68.75 & & & \\
\hline$\$ 155,000$ and over & 35 & 4.86 & & & \\
\hline \multicolumn{6}{|l|}{$\begin{array}{l}\text { Technology/engineering } \\
\text { degree }\end{array}$} \\
\hline No & 536 & 74.44 & & & \\
\hline Yes & 184 & 25.56 & & & \\
\hline \multicolumn{6}{|l|}{ Robot exposure online } \\
\hline No & 345 & 47.92 & & & \\
\hline Yes & 375 & 52.08 & & & \\
\hline Continuous measures & $M$ & $S D$ & Range & $n$ of items & $\alpha$ \\
\hline Robot use self-efficacy & 16.09 & 3.64 & $3-21$ & 3.00 & 0.88 \\
\hline \multicolumn{6}{|l|}{ Personality traits } \\
\hline Neuroticism [Big Five] & 10.76 & 5.14 & $3-21$ & 3.00 & 0.85 \\
\hline Extraversion [Big Five] & 11.32 & 4.81 & $3-21$ & 3.00 & 0.84 \\
\hline Openness [Big Five] & 15.36 & 3.81 & $3-21$ & 3.00 & 0.79 \\
\hline Agreeableness [Big Five] & 15.35 & 3.67 & $3-21$ & 3.00 & 0.62 \\
\hline Conscientiousness [Big Five] & 16.22 & 3.39 & $3-21$ & 3.00 & 0.67 \\
\hline
\end{tabular}

money to AI and robot opponents than those without previous experience with robots.

\section{DISCUSSION}

Trust is a crucial dimension in human-technology interaction. We investigated the extent to which participants trust robots or AI using a trust game experiment. We found out that, contrary to our hypotheses, opponent type (robot, AI or not specified control) had no significant effect on trust. However, opponents named jdrx894 were trusted more than those named Michael. The most trusted opponent was the robot jdrx894, and least trusted was Michael in the control group.

Hypotheses of the second part of our study were mostly confirmed, as we expected that technology education, online robot exposure, and robot use self-efficacy would predict trust
TABLE 4 | Linear regression analysis on money given to an Al or a robot opponent $(N=710)$.

\begin{tabular}{|c|c|c|c|c|}
\hline Measure & $B$ & SE B & $p$ & $\beta$ \\
\hline Age over 40 & 91.33 & 25.64 & $<0.001$ & 0.13 \\
\hline Female & -27.55 & 24.74 & 0.266 & -0.04 \\
\hline \multicolumn{5}{|l|}{ Occupational status } \\
\hline Student & Ref. & Ref. & Ref. & Ref. \\
\hline Works full or part time & -11.65 & 70.64 & 0.869 & -0.01 \\
\hline Other & -48.71 & 77.14 & 0.528 & -0.05 \\
\hline \multicolumn{5}{|l|}{ Household's gross annual income } \\
\hline$<\$ 35,000$ & -58.16 & 27.32 & 0.034 & -0.08 \\
\hline$\$ 35,000-\$ 154,999$ & Ref. & Ref. & Ref. & Ref. \\
\hline$\$ 155,000$ and over & -95.11 & 54.06 & 0.079 & -0.06 \\
\hline Technology/engineering degree & 58.85 & 29.37 & 0.045 & 0.08 \\
\hline Robot exposure online & 47.65 & 23.86 & 0.046 & 0.07 \\
\hline Robot use self-efficacy & 14.22 & 3.58 & $<0.001$ & 0.16 \\
\hline Neuroticism [Big Five] & 1.73 & 2.66 & 0.516 & 0.03 \\
\hline Extraversion [Big Five] & 0.92 & 2.63 & 0.727 & 0.01 \\
\hline Openness [Big Five] & 7.80 & 3.41 & 0.022 & 0.09 \\
\hline Agreeableness [Big Five] & 1.08 & 3.66 & 0.768 & 0.01 \\
\hline Conscientiousness [Big Five] & -12.79 & 4.23 & 0.003 & -0.14 \\
\hline
\end{tabular}

Those not identified as males or females $(n=10)$ were dropped from the model for estimation reasons.

toward robots and AI. The results were in line with previous research about the relevance of user experience and familiarity with robotics (Hancock et al., 2011) and robot use self-efficacy (Latikka et al., 2019). Exposure to online discussions might also have a positive impact on trust. Yet, this matter needs to be investigated in other studies, as research on this topic is scarce. However, the potential impact of online communities and discussions has been noted before (Moorhead et al., 2013; Keipi et al., 2017).

Our results also underline the relevance of personality in understanding human-technology interactions and trust. Based on the hypotheses concerning personality traits, we found evidence for a positive correlation between openness and trust toward robots and AI, which is in line with previous research related to personality factors and trust in general (Kaplan et al., 2015). In contrast to what Chien et al. (2016) found in their study about trust toward automation, our results suggest a negative association between conscientiousness and trust toward robots and AI. We found no relationship concerning the traits of agreeableness, extraversion, or neuroticism.

The results make sense from the perspective that people have become more exposed and accustomed to robots over time. Also, robots have been designed to be more attractive, approachable, and predictable based on, for example, gestures (e.g., Li et al., 2010; Sanders et al., 2011; Mou et al., 2020), whereas AI's image may be more abstract and distanced, although similar design attempts have been made in combining AI bots with humanlike virtual images (Araujo, 2018). Rich visual mental imagery has 
been found to affect how robots are perceived (Fortunati et al., 2015), and for these reasons, it might be easy for participants to trust a robot called jdrx894. According to the results of the experiment, participants showed lowest trust to the control group Michael who could be interpreted as another human. This could be explained by studies showing that people tend to consider others more selfish and negative than they actually are (Vuolevi and Van Lange, 2010; Van Lange, 2015). For these reasons, our participants might have been willing to think that robots are trustworthy. This would contrast the similarity-attraction hypothesis (Nass and Lee, 2001; Montoya and Horton, 2013). Another issue is gender. Our experiment included only a male opponent named Michael. This might have impacted the results, as males are generally perceived as less trustworthy than females in economic game experiments (Bohnet and Zeckhauser, 2004; Buchan et al., 2008).

Visual anonymity was an aspect of the experiment. We did not include any pictures or information about $\mathrm{AI}$ or robots because we wanted to measure the minimal conditions that might impact behavior in interactional settings, such as online customer service encounters. Our results based on a sample of participants from the United States suggest that software developers and service providers should not hide the true identity of intelligent nonhuman agents. Visual anonymity in the experimental context might also have an impact on behavior. In this type of experiment, players might consider the situation such that they would not ever meet the opponent again. This is different from normal face-toface encounters in everyday life, where trust or distrust of others might carry long-term consequences.

The analysis showed additional evidence for trust toward robots and AI. In line with established theories and empirical evidence (Hancock et al., 2011; Van Lange, 2015; Schaefer et al., 2016), predictors of trust were having a degree in technology or engineering, having prior experience and selfefficacy with robots, and exhibiting openness as a personality trait, confirming the hypotheses, for the most part. We also noted that exposure to online robot discussions predicted trust. It was interesting, however, that although prior experience has been found to associate with the acceptance of robots (Venkatesh, 2000; Nomura et al., 2006; Bartneck et al., 2007; Heerink et al., 2010), we found an interaction effect indicating that those who had robot use experience and high robot use self-efficacy gave lower sums of money to AI and robot opponents than those who did not have experience with robots. This interaction also reveals that despite being familiar with robotics, people might be also skeptical of intentions of robots and AI with higher skills. More studies on trust are needed from this perspective.

Our study is based on a minimal condition, giving few cues about the nature of robots and AI. Such minimal conditions are important, especially when analyzing trust and behavior online, where various cues are left out. Our control groups used only the human name Michael and nickname jdrx894 without describing them explicitly as humans, because we did not want to indicate to the participants that opponents might not be humans. This resulted in a reliable control condition. However, this decision is also a limitation of the study, as we cannot be sure that all participants interpreted the control group opponents as humans. Further limitations of our study were that there was no manipulation check to ensure that participants had paid attention to names or descriptions of opponents as robots or AI, or a check to ensure whether participants had understood how to maximize their gains on the trust game.

Future studies could, however, describe one of the experimental groups explicitly as humans. It would also be good to use female names, as the male name used in our study was considered less trustworthy than the nickname. It might also be possible to conduct an experiment with various types of robots and AI avatars using trust game settings. In addition, more studies on individual factors, such as personality, would be needed, as our results showed that they impacted trust. These types of factors could be crucial when introducing new technologies to people.

Robots and AI were not less trusted than the control group, which indicates that people are becoming more trusting toward new technology, at least in contexts where one needs to be able to trust the cognitive abilities and fairness of advanced technology. In other words, our results suggest that in some conditions, technological entities can be perceived as rational actors that, without hidden motivations and agendas, make more sensible and unselfish decisions than humans. This has potentially major implications for a variety of service sector fields. This finding can also be understood from a broader perspective, as a shift toward a "feeling economy" as the next generation of AI (Huang et al., 2019). People are currently impacted by public discussions about robots, and this was evident in our results, indicating that those who were more familiar with online robots showed more trust. However, we determined that those with prior experience using robots and very high robot use self-efficacy were not necessarily trusting. This hints that the current development of AI may also cause concern, for example, about the capabilities of machine learning and its ethical regulation among the most technologically knowledgeable and capable individuals.

\section{DATA AVAILABILITY STATEMENT}

The raw data supporting the conclusions of this article will be made available by the authors, without undue reservation.

\section{ETHICS STATEMENT}

The studies involving human participants were reviewed and approved by The Ethics Committee of the Tampere Region. The participants provided their informed consent to participate in this study.

\section{AUTHOR CONTRIBUTIONS}

AO contributed to the conceptualization, data collection, investigation, methodology, formal analysis, writing original draft, supervision, and funding acquisition. NS contributed to the conceptualization, data collection, investigation, methodology, 
reviewing and editing the manuscript, and visualization. RL contributed to the conceptualization, investigation, reviewing and editing the manuscript. AK contributed to the methodology, investigation, and review and editing the manuscript. All authors contributed to the article and approved the submitted version.

\section{REFERENCES}

Agarwal, R., Sambamurthy, V., and Stair, R. M. (2000). Research report: the evolving relationship between general and specific computer self-efficacy - an empirical assessment. Inf. Syst. Res. 11, 418-430. doi: 10.1287/isre.11.4.418. 11876

Araujo, T. (2018). Living up to the chatbot hype: the influence of anthropomorphic design cues and communicative agency framing on conversational agent and company perceptions. Comput. Hum. Behav. 85, 183-189. doi: 10.1016/j.chb. 2018.03.051

Ashraf, N., Bohnet, I., and Piankov, N. (2006). Decomposing trust and trustworthiness. Exp. Econ. 9, 193-208. doi: 10.1007/s10683-006-9122-4

Bandura, A. (1986). Social Foundations of Thought and Action: A Social Cognitive Theory. Englewood Cliffs, NJ: Prentice-Hall.

Bandura, A. (1997). Self-Efficacy: The Exercise of Control. New York, NY: Freeman.

Bartneck, C., Suzuki, T., Kanda, T., and Nomura, T. (2007). The influence of people's culture and prior experiences with Aibo on their attitude towards robots. AI Soc. 21, 217-230. doi: 10.1007/s00146-006-0052-7

Berg, J., Dickhaut, J., and McCabe, K. (1995). Trust, reciprocity, and social history. Games Econ. Behav. 10, 122-142. doi: 10.1006/game.1995.1027

Bjørnskov, C. (2012). How does social trust affect economic growth? Southern Econ. J. 78, 1346-1368. doi: 10.4284/0038-4038-78.4.1346

Bohnet, I., and Zeckhauser, R. (2004). Trust, risk and betrayal. J. Econ. Behav. Organ. 55, 467-484. doi: 10.1016/j.jebo.2003.11.004

Borenstein, J. (2011). Robots and the changing workforce. AI Soc. 26, 87-93. doi: 10.1007/s00146-009-0227-0

Brülhart, M., and Usunier, J.-C. (2011). Does the trust game measure trust? Econ. Lett. 115, 20-23. doi: 10.1016/j.econlet.2011.11.039

Buchan, N. R., Croson, R. T., and Solnick, S. (2008). Trust and gender: an examination of behavior and beliefs in the investment game. J. Econ. Behav. Organ. 68, 466-476. doi: 10.1016/j.jebo.2007.10.006

Buhrmester, M., Kwang, T., and Gosling, S. D. (2011). Amazon's mechanical turk: a new source of inexpensive, yet high-quality, data? Perspect. Psychol. Sci. 6, 3-5. doi: $10.1177 / 1745691610393980$

Camerer, C. F. (2003). Behavioral Game Theory. Experiments in Strategic Interaction. Princeton, NJ: Princeton University Press.

Cameron, D., de Saille, S., Collins, E., Aitken, J. M., Cheung, H., Chua, A., et al. (2021). The effect of social-cognitive recovery strategies on likability, capability and trust in social robots. Comput. Hum. Behav. 114:106561. doi: 10.1016/j.chb. 2020.106561

Chien, S. Y., Sycara, K., Liu, J. S., and Kumru, A. (2016). Relation between trust attitudes toward automation, Hofstede's cultural dimensions, and big five personality traits. Proc. Hum. Fact. Ergon. Soc. Annu. Meet. 60, 841-845. doi: $10.1177 / 1541931213601192$

Compeau, D. R., and Higgins, C. A. (1995). Computer self-efficacy: development of a measure and initial test. MIS Q. 19, 189-211. doi: 10.2307/249688

Cook, K. (ed.) (2001). Trust in Society. New York, NY: Russell Sage Foundation.

Correia, F., Alves-Oliveira, P., Maia, N., Ribeiro, T., Petisca, S., Melo, F. S., et al. (2016). "Just follow the suit! Trust in human-robot interactions during card game playing," in 2016 25th IEEE International Symposium on Robot and Human Interactive Communication (RO-MAN), New York, NY, 507-512. doi: 10.1109/ROMAN.2016.7745165

Correia, F., Petisca, S., Alves-Oliveira, P., Ribeiro, T., Melo, F. S., and Paiva, A. (2019). “I Choose ... YOU!" Membership preferences in human-robot teams. Auton. Robots 43, 359-373. doi: 10.1007/s10514-018-9767-9

De Graaf, M. M., and Allouch, S. B. (2013). Exploring influencing variables for the acceptance of social robots. Rob. Auton. Syst. 61, 1476-1486. doi: 10.1016/j. robot.2013.07.007

Delhey, J., and Newton, K. (2003). Who trusts?: the origins of social trust in seven societies. Eur. Soc. 5, 93-137. doi: 10.1080/1461669032000072256

\section{FUNDING}

This research has received funding from the Finnish Cultural Foundation (Robots and Us Project, 2018-2020, PIs Jari Hietanen, AO, and Veikko Sariola).

Digman, J. M. (1990). Personality structure: emergence of the five-factor model. Annu. Rev. Psychol. 41, 417-440. doi: 10.1146/annurev.ps.41.020190.002221

Dignum, V. (2018). Ethics in artificial intelligence: introduction to the special issue. Ethics Inf. Technol. 20, 1-3. doi: 10.1007/s10676-018-9450-z

Dunning, D., Fetchenhauer, D., and Schloüsser, T. M. (2012). Trust as a social and emotional act: noneconomic considerations in trust behavior. J. Econ. Psychol. 33, 686-694. doi: 10.1016/j.joep.2011.09.005

Eastin, M. S., and LaRose, R. (2000). Internet self-efficacy and the psychology of the digital divide. J. Comput. Med. Commun. 6. doi: 10.1111/j.1083-6101.2000. tb00110.x

Eurobarometer (2012). Public Attitudes Towards Robots [Special Eurobarometer 382]. Brussels: European Commission.

Evans, A. M., and Revelle, W. (2008). Survey and behavioral measurements of interpersonal trust. J. Res. Personal. 42, 1585-1593. doi: 10.1016/j.jrp.2008. 07.011

Fariña, F., Arce, R., Sobral, J., and Carames, R. (1991). Predictors of anxiety towards computers. Comput. Hum. Behav. 7, 263-267. doi: 10.1016/0747-5632(91) 90014-R

Fehr, E., and Gintis, H. (2007). Human motivation and social cooperation: experimental and analytical foundations. Annu. Rev. Sociol. 33, 43-64. doi: 10.1146/annurev.soc.33.040406.131812

Ferreira, B. Q., Karipidou, K., Rosa, F., Petisca, S., Alves-Oliveira, P., and Paiva, A. (2016). "A study on trust in a robotic suitcase," in Social Robotics. ICSR 2016. Lecture Notes in Computer Science, Vol. 9979, eds A. Agah, J. J. Cabibihan, A. Howard, M. Salichs, and H. He (Cham: Springer), doi: 10.1007/978-3-31947437-3_18

Fortunati, L., Esposito, A., Sarrica, M., and Ferrin, G. (2015). Children's knowledge and imaginary about robots. Int. J. Soc. Rob. 7, 685-695. doi: 10.1007/s12369015-0316-9

Freitag, M., and Traunmüller, R. (2009). Spheres of trust: an empirical analysis of the foundations of particularised and generalised trust. Eur. J. Polit. Res. 48, 782-803. doi: 10.1111/j.1475-6765.2009.00849.x

Frey, C. B., and Osborne, M. A. (2017). The future of employment: how susceptible are jobs to computerisation? Technol. Forecast. Soc. Change 114, 254-280. doi: 10.1016/j.techfore.2016.08.019

Gefen, D. (2000). E-commerce: the role of familiarity and trust. Omega 28, 725-737.

Gnambs, T., and Appel, M. (2019). Are robots becoming unpopular? Changes in attitudes towards autonomous robotic systems in Europe. Comput. Hum. Behav. 93, 53-61. doi: 10.1016/j.chb.2018.11.045

Goetz, J., Kiesler, S., and Powers, A. (2003). "Matching robot appearance and behavior to tasks to improve human-robot cooperation," in The 12th IEEE International Workshop on Robot and Human Interactive Communication, 2003. Proceedings. ROMAN 2003, Millbrae, CA, 55-60. doi: 10.1109/ROMAN. 2003.1251796

Gravetter, F. J., and Wallnau, L. B. (2017). Introduction to the Statistic. Essentials of Statistics for the Behavioral Sciences. Belmont, CA: Wadsworth.

Hancock, P. A., Billings, D. R., Schaefer, K. E., Chen, J. Y., De Visser, E. J., and Parasuraman, R. (2011). A meta-analysis of factors affecting trust in humanrobot interaction. Hum. Factors 53, 517-527. doi: 10.1177/0018720811417254

Hancock, P. A., Kessler, T. T., Kaplan, A. D., Brill, J. C., and Szalma, J. L. (2020). Evolving trust in robots: specification through sequential and comparative meta-analyses. Hum. Factors doi: 10.1177/0018720820922080 Advance online publication

Hardin, R. (2005). Trust. Oxford: Polity.

Hasan, B. (2006). Delineating the effects of general and system-specific computer self- efficacy beliefs on IS acceptance. Inf. Manag. 43, 565-571. doi: 10.1016/j. im.2005.11.005

Heerink, M. (2011). "). Exploring the influence of age, gender, education and computer experience on robot acceptance by older adults," in Proceedings of the 
6th International Conference on Human-Robot Interaction (HRI '11), New York, NY: Association for Computing Machinery, 147-148. doi: 10.1145/1957656. 1957704

Heerink, M., Kroüse, B., Evers, V., and Wielinga, B. (2010). Assessing acceptance of assistive social agent technology by older adults: the almere model. Int. J. Soc. Rob. 2, 361-375. doi: 10.1007/s12369-010-0068-5

Hitlin, P. (2016). Research in the Crowdsourcing Age, a Case Study: How Scholars, Companies and Workers are Using Mechanical Turk, a "gig economy" Platform, for Tasks Computers Can't Handle. Washington, DC: Pew Research Center.

Hoff, K. A., and Bashir, M. (2015). Trust in automation: integrating empirical evidence on factors that influence trust. Hum. Factors 57, 407-434. doi: 10.1177/ 0018720814547570

Hsu, M.-H., and Chiu, C.-M. (2004). Internet self-efficacy and electronic service acceptance. Decis. Support Syst. 38, 369-381. doi: 10.1016/j.dss.2003.08.001

Huang, M. H., Rust, R., and Maksimovic, V. (2019). The feeling economy: managing in the next generation of artificial intelligence (AI). Calif. Manag. Rev. 61, 43-65. doi: 10.1177/0008125619863436

Huang, M. H., and Rust, R. T. (2018). Artificial intelligence in service. J. Serv. Res. 21, 155-172. doi: 10.1177/1094670517752459

Huff, C., and Tingley, D. (2015). Who are these people?" Evaluating the demographic characteristics and political preferences of MTurk survey respondents. Res. Polit. 2, 1-12. doi: 10.1177/2053168015604648

International Organization for Standardization [ISO] (2014). Robots and Robotic Devices - Safety Requirements for Personal care Robots. Avaliable at: https: //www.iso.org/obp/ui/\#iso:std:iso:13482:ed-1:v1:en (accessed November 13, 2020).

John, O. P., Naumann, L. P., and Soto, C. J. (2008). "Paradigm shift to the integrative Big Five trait taxonomy," in Handbook of Personality: Theory and Research, 3rd Edn, eds O. P. John, R. W. Robins, and L. A. Pervin (New York, NY: The Guilford Press), 114-158.

Johnson, N. D., and Mislin, A. A. (2011). Trust game: a meta-analysis. J. Econ. Psychol. 32, 865-889. doi: 10.1016/j.joep.2011.05.007

Kaplan, S. C., Levinson, C. A., Rodebaugh, T. L., Menatti, A., and Weeks, J. W. (2015). Social anxiety and the big five personality traits: the interactive relationship of trust and openness. Cogn. Behav. Ther. 44, 212-222. doi: 10. 1080/16506073.2015.1008032

Keipi, T., Näsi, M., Oksanen, A., and Räsänen, P. (2017). Online Hate and Harmful Content: Cross-National Perspectives. New York, NY: Routledge, doi: 10.4324/ 9781315628370

Kennedy, R., Clifford, S., Burleigh, T., Waggoner, P., Jewell, R., and Winter, N. (2020). The shape of and solutions to the MTurk quality crisis. Polit. Sci. Res. Methods 8, 614-629. doi: 10.1017/psrm.2020.6

Lang, F. R., John, D., Lüdtke, O., Schupp, J., and Wagner, G. G. (2011). Short assessment of the big five: robust across survey methods except telephone interviewing. Behav. Res. Methods 43, 548-567. doi: 10.3758/s13428-011-0066-z

Latikka, R., Turja, T., and Oksanen, A. (2019). Self-efficacy and acceptance of robots. Comput. Hum. Behav. 93, 157-163. doi: 10.1016/j.chb.2018. 12.017

Lee, J. D., and See, K. A. (2004). Trust in automation: designing for appropriate reliance. Hum. Factors 46, 50-80. doi: 10.1518/hfes.46.1.50_30392

Levin, K. (1935). A Dynamic Theory of Personality. Selected Papers. New York, NY: McGraw-Hill.

Li, D., Rau, P. P., and Li, Y. (2010). A cross-cultural study: effect of robot appearance and task. Int. J. Soc. Rob. 2, 175-186. doi: 10.1007/s12369-0100056-9

Liu, H. Y., and Zawieska, K. (2017). From responsible robotics towards a human rights regime oriented to the challenges of robotics and artificial intelligence. Ethics Inf. Technol. 22, 321-333. doi: 10.1007/s10676-017-9443-3

Makridakis, S. (2017). The forthcoming artificial intelligence (AI) revolution: its impact on society and firms. Futures 90, 46-60. doi: 10.1016/j.futures.2017. 03.006

Mathur, M. B., and Reichling, D. B. (2016). Navigating a social world with robot partners: a quantitative cartography of the Uncanny Valley. Cognition 146, 22-32. doi: 10.1016/j.cognition.2015.09.008

Mayer, R. C., Davis, J. H., and Schoorman, F. D. (1995). An integrative model of organizational trust. Acad. Manag. Rev. 20, 709-734. doi: 10.5465/amr.1995. 9508080335
Montoya, R. M., and Horton, R. S. (2013). A meta-analytic investigation of the processes underlying the similarity-attraction effect. J. Soc. Pers. Relationsh. 30, 64-94. doi: 10.1177/0265407512452989

Mooradian, T., Renzl, B., and Matzler, K. (2006). Who trusts? Personality, trust and knowledge sharing. Manag. Learn. 37, 523-540. doi: 10.1177/ 1350507606073424

Moorhead, S. A., Hazlett, D. E., Harrison, L., Carroll, J. K., Irwin, A., and Hoving, C. (2013). A new dimension of health care: systematic review of the uses, benefits, and limitations of social media for health communication. J. Med. Internet Res. 15:e85. doi: 10.2196/jmir.1933

Moss, A. J., Rosenzweig, C., Robinson, J., and Litman, L. (2020). Is it ethical to use Mechanical Turk for behavioral research? Relevant data from a representative survey of MTurk participants and wages. PsyArXiv [Preprint]. Available online at: https://psyarxiv.com/jbc9d/ (accessed November 13, 2020).

Mou, Y., Shi, C., Shen, T., and Xu, K. (2020). A systematic review of the personality of robot: mapping its conceptualization, operationalization, contextualization and effects. Int. J. Hum. Comput. Interact. 36, 591-605. doi: 10.1080/10447318. 2019.1663008

Nass, C., and Lee, K. M. (2001). Does computer-synthesized speech manifest personality? experimental tests of recognition, similarity-attraction, and consistency-attraction. J. Exp. Psychol. 7, 171-181. doi: 10.1037/1076-898X.7. 3.171

Nass, C., and Moon, Y. (2000). Machines and mindlessness: social responses to computers. J. Soc. Issues 56, 81-103.

Nomura, T., Kanda, T., and Suzuki, T. (2006). Experimental investigation into influence of negative attitudes toward robots on human-robot interaction. $A I$ Soc. 20, 138-150. doi: 10.1007/s00146-005-0012-7

Nooteboom, B. (2011). The dynamics of trust: communication, action and third parties. Comp. Sociol. 10, 166-185. doi: 10.1163/156913311X566553

Oksanen, A., Savela, N., and Latikka, R (2019). Trust on Robots and AI: A Social Psychological Trust Game Experiment. Charlottesville, VA: Center for Open Science. Available online at: https://osf.io/x2dms

Paolacci, G., and Chandler, J. (2014). Inside the turk: understanding mechanical turk as a participant pool. Curr. Dir. Psychol. Sci. 23, 184-188. doi: 10.1177/ 0963721414531598

Putnam, R. (2000). Bowling Alone: The Collapse and Revival of American Community. New York, NY: Simon \& Schuster.

Rahman, M. S., Ko, M., Warren, J., and Carpenter, D. (2016). Healthcare technology self- efficacy (HTSE) and its influence on individual attitude: an empirical study. Comput. Hum. Behav. 58, 12-24. doi: 10.1016/j.chb.2015. 12.016

Reeves, B., and Nass, C. (1996). The Media Equation: How People Treat Computers, Television, and New Media Like Real People and Places. New York, NY: Cambridge University Press.

Reich, N., and Eyssel, F. (2013). Attitudes towards service robots in domestic environments: the role of personality characteristics, individual interests, and demographic variables. Paladyn J. Behav. Rob. 4, 123-130. doi: 10.2478/pjbr2013-0014

Reich-Stiebert, N., and Eyssel, F. (2015). Learning with educational companion robots? Toward attitudes on education robots, predictors of attitudes, and application potentials for education robots. Int. J. Soc. Robot. 7, 875-888. doi: 10.1007/s12369-015-0308-9

Robert, L. P. (2018). "Personality in the human robot interaction literature: a review and brief critique," in Proceedings of the 24th Americas Conference on Information Systems, New Orleans, LA.

Rothstein, B., and Uslaner, E. M. (2005). All for all: equality, corruption, and social trust. World Polit. 58, 41-72. doi: 10.1353/wp.2006.0022

Russell, S., Hauert, S., Altman, R., and Veloso, M. (2015). Ethics of artificial intelligence. Nature 521, 415-416.

Samson, K., and Kostyszyn, P. (2015). Effects of cognitive load on trusting behavior-An experiment using the trust game. PLoS One 10:e0127680. doi: 10.1371/journal.pone.0127680

Sanders, T., Oleson, K. E., Billings, D. R., Chen, J. Y., and Hancock, P. A. (2011). A model of human-robot trust: theoretical model development. Proc. Hum. Factors Ergon. Soc. Annu.Meet. 55, 1432-1436. doi: 10.1177/1071181311551298

Schaefer, K. E., Chen, J. Y., Szalma, J. L., and Hancock, P. A. (2016). A meta-analysis of factors influencing the development of trust in automation: implications 
for understanding autonomy in future systems. Hum. Factors 58, 377-400. doi: $10.1177 / 0018720816634228$

Scopelliti, M., Giuliani, M. V., and Fornara, F. (2005). Robots in a domestic setting: a psychological approach. Univ. Access Inf. Soc. 4, 146-155. doi: 10.1007/ s10209-005-0118-1

Simon, H. A. (1977). What computers mean for man and society. Science 195, 1186-1191. doi: 10.1126/science.195.4283.1186

Simpson, J. A. (2007a). "Foundations of interpersonal trust," in Social Psychology: Handbook of Basic Principles, eds A. W. Kruglanski and E. T. Higgins (New York, NY: Guilford), 587-607.

Simpson, J. A. (2007b). Psychological foundations of trust. Curr. Dir. Psychol. Sci. $16,264-268$.

Stolle, D. (2002). Trusting strangers: the concept of generalized trust in perspective. Osterreichische Zeitschrift fur Politikwissenschaft 31, 397-412.

Tabachnick, B. G., and Fidell, L. S. (2013). Using Multivariate Statistics, 6th Edn. Boston, MA: Pearson.

Tanis, M., and Postmes, T. (2003). Social cues and impression formation in CMC. J. Commun. 53, 676-693. doi: 10.1111/j.1460-2466.2003.tb0 2917.x

Tanis, M., and Postmes, T. (2005). A social identity approach to trust: interpersonal perception, group membership and trusting behaviour. Eur. J. Soc. Psychol. 35, 413-424. doi: 10.1002/ejsp.256

Trifletti, E., and Capozza, D. (2011). Examining group-based trust with the investment game. Soc. Behav. Personal. 39, 405-410. doi: 10.2224/sbp.2011.39. 3.405

Turja, T., Rantanen, T., and Oksanen, A. (2019). Robot use self-efficacy in healthcare work (RUSH): development and validation of a new measure. AI Soc. 34, 137-143. doi: 10.1007/s00146-017-0751-2

U. S. Census Bureau (2010). Profile of General Population and Housing Characteristics: 2010. Available online at: https://data.census.gov/cedsci/table? q=\%29.\%20Profile $\% 20$ of $\% 20$ general $\% 20$ population $\% 20$ and $\% 20$ housing $\%$ 20characteristics\&tid=DECENNIALDPCD1132010.113DP1 (accessed November 13, 2020).

Uslaner, E. M. (2000). Producing and consuming trust. Polit. Sci. Q. 115, 569-590. doi: $10.2307 / 2657610$

Uslaner, E. M. (2002). The Moral Foundations of Trust. Cambridge: Cambridge University Press.

Van Den Bos, W., van Dijk, E., Westenberg, M., Rombouts, S. A., and Crone, E. A. (2009). What motivates repayment? Neural correlates of reciprocity in the Trust Game. Soc. Cogn. Affect. Neurosci. 4, 294-304. doi: 10.1093/scan/ nsp009

Van Deursen, A. J., and Van Dijk, J. A. (2014). The digital divide shifts to differences in usage. New Med. Soc. 16, 507-526. doi: 10.1177/1461444813 487959

Van Lange, P. A. (2015). Generalized trust: four lessons from genetics and culture. Curr. Dir. Psychol. Sci. 24, 71-76. doi: 10.1177/0963721414552473

Venkatesh, V. (2000). Determinants of perceived ease of use: integrating control, intrinsic motivation, and emotion into the technology acceptance model. Inf. Syst. Res. 11, 342-365. doi: 10.1287/isre.11.4.342.11872

Verardi, V., and Croux, C. (2009). Robust regression in Stata. Stata J. 9, 439-453. doi: 10.1177/1536867X0900900306

Vuolevi, J. H. K., and Van Lange, P. A. M. (2010). Beyond the information given: the power of a belief in self-interest. Eur. J. Soc. Psychol. 40, 26-34. doi: 10.1002/ ejsp.711

Waternaux, C. M. (1976). Asymptotic distribution of the sample roots for a nonnormal population. Biometrika 63, 639-645. doi: 10.1093/biomet/63.3.639

Winfield, A. F., Michael, K., Pitt, J., and Evers, V. (2019). Machine ethics: the design and governance of ethical AI and autonomous systems. Proc. IEEE 107, 509-517. doi: 10.1109/JPROC.2019.2900622

Xin, Z., Liu, Y., Yang, Z., and Zhang, H. (2016). Effects of minimal social cues on trust in the investment game. Asian J. Soc. Psychol. 19, 235-243. doi: 10.1111/ ajsp. 12143

Yagoda, R. E., and Gillan, D. J. (2012). You want me to trust a ROBOT? The development of a human-robot interaction trust scale. Int. J. Soc. Rob. 4, 235-248. doi: 10.1007/s12369-012-0144-0

Zhang, B., and Dafoe, A. (2019). Artificial Intelligence: American Attitudes and Trends. Oxford: University of Oxford, doi: 10.2139/ssrn.3312874

Conflict of Interest: The authors declare that the research was conducted in the absence of any commercial or financial relationships that could be construed as a potential conflict of interest.

Copyright (c) 2020 Oksanen, Savela, Latikka and Koivula. This is an open-access article distributed under the terms of the Creative Commons Attribution License (CC BY). The use, distribution or reproduction in other forums is permitted, provided the original author(s) and the copyright owner(s) are credited and that the original publication in this journal is cited, in accordance with accepted academic practice. No use, distribution or reproduction is permitted which does not comply with these terms. 


\section{APPENDIX A}

The following is an example of information given for the trust game study participants.

We now invite you to participate in an imaginary game. In the game you play against another player, and you will make decisions about how to distribute a sum of money between the two of you.

At the beginning of the game, you receive \$1,000. You can decide whether you keep this whole sum to yourself or whether you share a part or all of it with the player that you are playing against. If you give money to the other player, we will triple the sum that you give. So, if you give \$500, the other player receives $\$ 1,500$. Then, it is up to the other player to decide how much money to return to you. As an example, if the person returns half, you will end up with $\$ 500+\$ 750=\$ 1,250$ at the end of the game. The other player may also choose not to return anything, which would mean that you win only the $\$ 500$ that you kept to yourselffrom the beginning.

The more money you obtain, the more successful you will be!

Name of the opponent: Michael, an artificial intelligence.

Fill in the amount in this box (between $\$ 0-\$ 1,000$ ).

\section{APPENDIX B}

TABLE A1 | Robust regression analysis on money given to an Al or a robot opponent $(N=710)$.

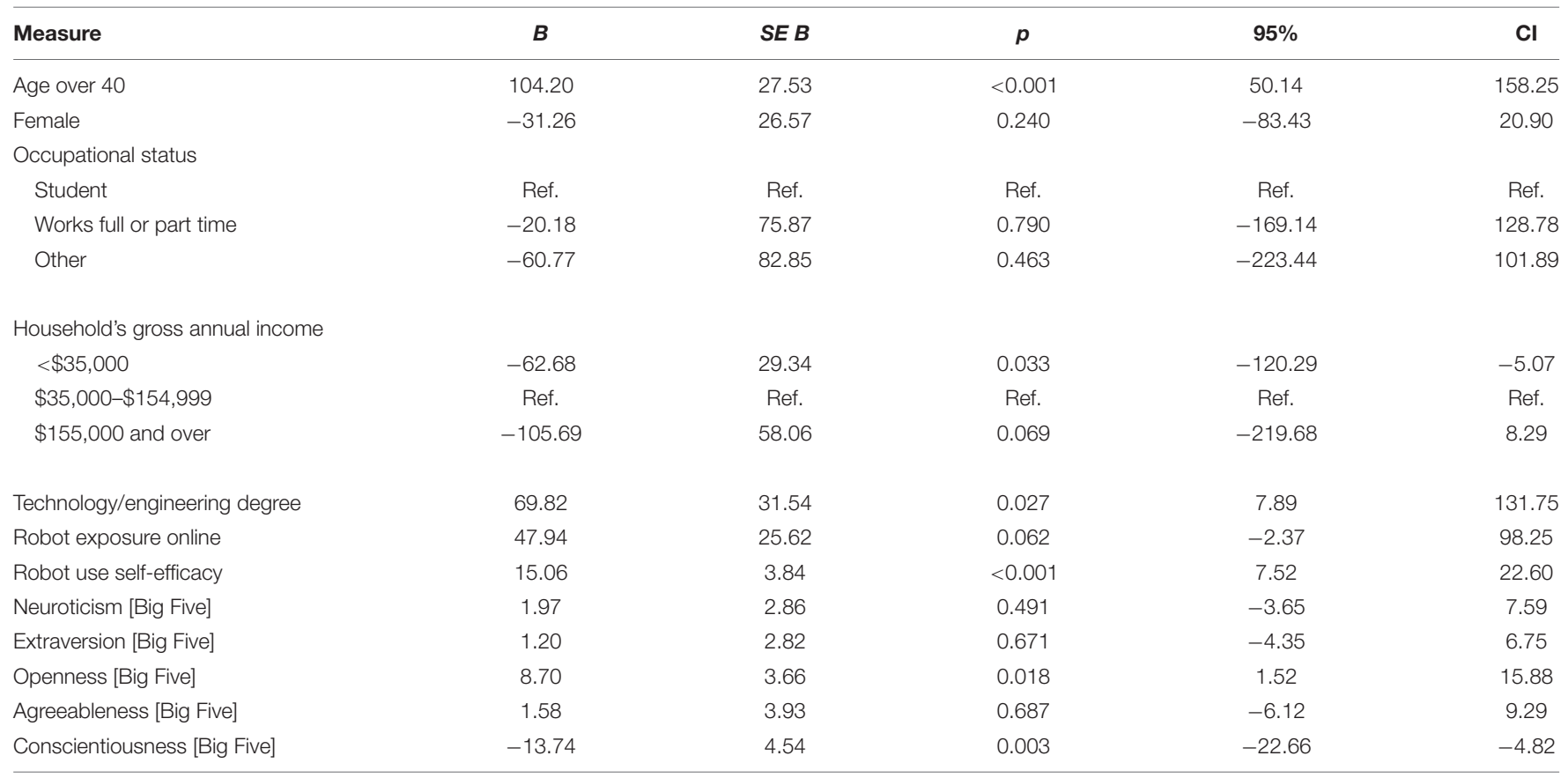

Those not identified as males or females $(n=10)$ were dropped from the model for estimation reasons. 


\section{APPENDIX C}

TABLE A2 | Additional linear regression analysis on money given to an Al or a robot opponent $(N=710)$.

\begin{tabular}{|c|c|c|c|c|}
\hline Measure & $B$ & SE B & $p$ & $\beta$ \\
\hline Age over 40 & 88.23 & 25.63 & 0.001 & 0.13 \\
\hline Female & -29.98 & 24.74 & 0.226 & -0.05 \\
\hline \multicolumn{5}{|l|}{ Occupational status } \\
\hline Student & Ref. & Ref. & Ref. & Ref. \\
\hline Works full or part time & -4.18 & 70.74 & 0.953 & 0.00 \\
\hline Other & -38.63 & 77.38 & 0.618 & -0.04 \\
\hline \multicolumn{5}{|l|}{ Household's gross annual income } \\
\hline$<\$ 35,000$ & -55.18 & 27.39 & 0.044 & -0.08 \\
\hline$\$ 35,000-\$ 154,999$ & Ref. & Ref. & Ref. & Ref. \\
\hline$\$ 155,000$ and over & -95.22 & 54.06 & 0.079 & -0.06 \\
\hline Technology/engineering degree & 65.62 & 29.92 & 0.029 & 0.09 \\
\hline Robot exposure online & 47.72 & 23.89 & 0.046 & 0.07 \\
\hline Robot use experience & 247.51 & 129.09 & 0.056 & 0.37 \\
\hline Robot use self-efficacy & 18.16 & 4.01 & $<0.001$ & 0.20 \\
\hline Neuroticism [Big Five] & 1.73 & 2.66 & 0.516 & 0.03 \\
\hline Extraversion [Big Five] & 1.05 & 2.63 & 0.690 & 0.02 \\
\hline Openness [Big Five] & 7.87 & 3.40 & 0.021 & 0.09 \\
\hline Agreeableness [Big Five] & 1.17 & 3.65 & 0.749 & 0.01 \\
\hline Conscientiousness [Big Five] & -12.50 & 4.24 & 0.003 & -0.13 \\
\hline Robot use experience $\times$ robot use self-efficacy & -15.88 & 7.63 & 0.038 & -0.40 \\
\hline
\end{tabular}

Those not identified as males or females $(n=10)$ were dropped from the model for estimation reasons. 